\title{
Do Conceito de Estrutura Narrativa à sua Crítica
}

\author{
André Guirland Vieira ${ }^{12}$ \\ Universidade Federal do Rio Grande do Sul \\ Centro de Estudos Junguianos C. A. Meier
}

\begin{abstract}
Resumo
O presente trabalho constitui-se em uma revisão das principais teorias responsáveis pela elaboração do conceito de estrutura narrativa a partir dos anos sessenta e de sua crítica, em estudos publicados nos anos oitenta. Inicia apresentando a gênese do conceito de narrativa e seu desenvolvimento, na lingüística e, paralelamente, na psicologia. Neste trabalho, mostramos que os estudos da narrativa sofreram uma mudança de enfoque, desde o estudo do modo como representamos nossas estórias, até o estudo de como construímos uma representação da experiência do tempo e do mundo.

Palavras-chave: Estrutura narrativa; narrativa; representação; hermenêutica.
\end{abstract}

\section{From the Concept of Narrative Structure to its Criticism}

\begin{abstract}
The present work consists of a review of the main theories responsible for the construction of the concept of narrative structure since the sixties and its criticism, in essays published in the eighties. It begins presenting the genesis of the concept of narrative and its development in Linguistic and also in Psychology. This essay shows that the study of narrative went through changes of point of view, from the study of the way we represent our stories to the study of how we build a representation of the experience of the time and the world.

Keywords: Narrative structure; narrative; representation; hermeneutics.
\end{abstract}

O que é a narrativa, e como pode ser definida? $\mathrm{Na}$ verdade, os primeiros estudos da narrativa começaram a partir da Poética de Aristóteles (1992), escritos em torno do ano de 335 a.C. A profundidade com que este autor analisou a tragédia foi tão grande que até hoje esta permanece sendo uma obra de referência para o entendimento da narrativa. O problema da narrativa foi retomado mais recentemente por Vladimir Propp (1928/ 1983) que, analisando os contos de fada russos, lançou os alicerces da atual narratologia. Em seu trabalho, Propp $(1928 / 1983)$ se propõe a fazer uma morfologia dos contos de fada (chamados por ele de contos maravilhosos). Como morfologia, o autor entende uma descrição dos contos segundo as suas partes constitutivas e as relações destas partes entre si e com o conjunto. Analisando e comparando a distribuição dos motivos em diversos contos, Propp descobriu que muitas vezes os contos emprestam as mesmas ações a personagens diferentes. Muitas são as situações, quando comparamos

\footnotetext{
1 Endereço para correspondência: Rua Criciúma, 173, Porto Alegre, RS. 91770-240, Fone: (51) 3248.8948. E-mail: andre.vieira@ufrgs.br

2 O presente artigo foi escrito na disciplina "Teorias do Desenvolvimento II”, do Curso de Pós-Graduação em Psicologia do Desenvolvimento da UFRGS,
}

contos diferentes, que se resumem numa mesma ação na qual o que muda são os nomes e os atributos das personagens, mas não suas funções. Assim, ele propõe um estudo dos contos a partir das funções das personagens. "No estudo do conto, a questão de saber o que fazem as personagens é a única coisa que importa; quem faz qualquer coisa e como o faz são questões acessórias" (Propp, 1928/1983, p. 59).

Assim, as funções das personagens representam as partes fundamentais do conto. Propp (1928/1983) define função como "a ação de uma personagem definida do ponto de vista de seu significado no desenrolar da intriga" (p. 59). Isto porque, atos idênticos podem ter significados diferentes e assumir funções diferentes na medida em que os elementos morfológicos da ação, sempre em relação ao contexto do conto, sejam diferentes. Propp chega a quatro teses fundamentais. 1) Os elementos constantes permanentes, do conto são as funções das personagens, quaisquer que sejam estas personagens e qualquer que seja o modo como são preenchidas estas funções. As funções são as partes constitutivas fundamentais do conto. 2) $\mathrm{O}$ número das funções do conto maravilhoso é limitado. 3) A sucessão das funções é sempre idêntica. 4) Todos os contos maravilhosos pertencem ao mesmo tipo no que diz respeito à estrutura. 
Devemos ter em mente que as teses citadas aqui só dizem respeito ao folclore, não constituindo uma particularidade do conto enquanto conto, assim o conto enquanto categoria literária não está submetida a estas regras.

As funções do conto maravilhoso se resumem a trinta e uma, das quais as sete primeiras constituem a parte preparatória do conto. A intriga propriamente dita se origina no momento em que se pratica a malfeitoria. Todas estas funções nem sempre existem quando tomado um conto particular, mas a ordem em que surgem no desenrolar da ação é sempre a mesma. Os contos principiam por uma exposição de uma situação inicial, que não se caracteriza como uma função, mas constitui um elemento morfológico importante. Em seguida principiam as funções. I - Um dos membros da família afasta-se de casa. II- Ao herói impõe-se uma interdição. III - A interdição é transgredida. IV - O agressor tenta obter informações. V - O agressor recebe informações sobre a sua vítima. VI - O agressor tenta enganar a sua vítima para se apoderar dela ou dos seus bens. VII - A vítima deixa-se enganar e ajuda assim o seu inimigo sem o saber. VIII - O agressor faz mal a um dos membros da família ou prejudica-o. VIII - (a) Falta qualquer coisa a um dos membros da família; um dos membros da família deseja possuir qualquer coisa. X - O herói-que-demanda aceita ou decide agir. XI - O herói deixa a casa. XII - O herói passa por uma prova, um questionário, um ataque, etc., que o preparam para o recebimento de um objeto ou de um auxiliar mágico. XIII - O herói reage às ações do futuro doador. XIV - O objeto mágico é posto à disposição do herói. XV - O herói é transportado, conduzido ou levado perto do local onde se encontra o objetivo de sua demanda. XVI - O herói e seu agressor confrontam-se em combate. XVII - O herói recebe uma marca. XVIII - O agressor é vencido. XIX - A malfeitoria inicial ou a falta são reparados. XX - O herói volta. XXI - O herói é perseguido. XXII - O herói é socorrido. XXIII - O herói chega incógnito à sua casa ou a outro país. XXIV - Um falso herói faz valer pretensões falsas. XXV - Propõe-se ao herói uma tarefa difícil. XXVI - A tarefa é cumprida. XXVII - O herói é reconhecido. XXVIII O falso herói ou o agressor, o mau é desmascarado. XXIX - O herói recebe uma nova aparência. XXX - O falso herói ou o agressor é punido. XXXI - O herói casa-se e sobe ao trono.

Estas funções são repartidas entre as personagens segundo certas esferas. Estas esferas correspondem às personagens que cumprem as funções. Encontramos no conto maravilhoso sete personagens com suas respectivas esferas de ação: A esfera de ação do agressor, a esfera de ação do doador, a esfera de ação do auxiliar, a esfera de ação da princesa e do seu pai, a esfera de ação do mandatário, a esfera de ação do herói, a esfera de ação do falso herói. As esferas de ação se repartem entre as personagens do conto segundo três possibilidades: A esfera de ação corresponde exatamente à personagem. Uma única personagem ocupa várias esferas de ação. Uma só esfera de ação divide-se entre várias personagens.

Segundo Propp (1928/1983), o texto do conto pode ainda se dividir em seqüências.

"Podemos chamar conto maravilhoso, do ponto de vista morfológico, a qualquer desenrolar de ação que parte de uma malfeitoria ou de uma falta, e que passa por funções intermediárias para ir acabar em casamento ou em outras funções utilizadas como desfecho. A função limite pode ser a recompensa, alcançar o objeto desejado ou, de uma maneira geral, a reparação da malfeitoria, o socorro e a salvação durante a perseguição, etc. Chamamos a este desenrolar de ação uma seqüência. Cada nova malfeitoria ou prejuízo, cada nova falta dá lugar a uma nova seqüência. Um conto pode ter várias seqüências, e quando se analisa um texto, é necessário em primeiro lugar determinar de quantas seqüências este se compõe" (Propp, 1928/1983, p. 144).

Finalmente, segundo Proop (1928/1983), as outras partes constitutivas do conto seriam os elementos de ligação; as motivações; as formas de entrada em cena dos personagens, como o encontro com Baba Yaga; os elementos acessórios atributivos, como a casinha de Baba Yaga ou os seus pés de argila. É de grande importância a abordagem funcional dos elementos do conto. Isto porque, o fato de podermos trabalhar com funções nos permitirá a construção de uma estrutura do conto. Assim, Propp será o primeiro a chamar a atenção para a forma estrutural do enunciado narrativo. Haja visto que Propp será um precursor do estruturalismo.

Bremond (1966) irá fazer uma profunda revisão dos trabalhos de Propp, propondo como modelo para os enunciados narrativos uma estrutura triádica. Sua proposta de esquema narrativo não mais se limitará ao conto folclórico, podendo ser expandida para as narrativas em geral. A partir desse momento, falar-se-á de uma estrutura dos enunciados narrativos.

"Partindo do fato que a natureza cronológica da estória implica que um evento $1^{\circ}$ comece (= antes), $2^{\circ}$ se desenvolva (= durante) e termine (= depois), segundo uma relação do conseqüente ao antecedente, Bremond estabelece uma lógica depossibilidades que esclarece o encadeamento tanto das ações, como das virtualidades e das atualizações" (Adam, 1985, p. 26).

Segundo Adam (1985), Bremond parte do princípio de que o processo narrativo apresenta uma situação lógica na qual atuam três papéis básicos: vítima, agressor e ajudante, que se organizam segundo o seguinte encadeamento. 
Degradação $\rightarrow$ Melhora $\rightarrow$ Ajuda

em curso e a evitar / da situação da vítima / demandada de um ajudante.

Se, ao final do processo, a ajuda é recebida, então a melhora será obtida e a degradação evitada. Por outro lado, se o processo de ajuda falha ou não é iniciado, não haverá melhora e a degradação não será evitada. Adam (1985), ao revisitar os trabalhos de Bremond (1966), salienta que a maior parte das narrativas repousam sobre a alternância entre as fases de degradação e melhora, de equilíbrio e de desequilíbrio.

Os trabalhos de Propp e Bremond nos dão uma primeira visão do que poderíamos chamar de unidade mínima da narrativa: a proposição narrativa. Adam (1985) define proposição narrativa como uma combinação de uma ou mais funções com um ou mais atores. "Uma proposição narrativa se apresenta como um predicado relacionado a 'n' argumentos-papéis narrativos' (p. 37). Isto de forma que o predicado organize os elementos e distribua os papéis. Tomemos um exemplo do próprio Adam. A seguinte proposição narrativa: Margarida ameaçou seu marido com um rolo de massa implica uma série de predicados qualificativos que marcam o estado de ser das personagens:

- A2 É o marido de A1.

- A2 É um homem.

- A1 É uma mulher braba.

- A3 É um utensílio utilizado em uma cena estereotipada.

Esta proposição também implica um predicado funcional (um fazer):

- A1 ameaça A2 através de A3.

Adam propõe três lugares potenciais para a participação na proposição narrativa. Assim, há o Agente (A1), que inicia a ação ou cuja intervenção modifica o curso das coisas; o Paciente (A2), que se submete às transformações; e por fim o Objeto (A3), que ocupa o lugar de instrumento. As proposições narrativas irão se agrupar, formando assim o que poderíamos chamar de um texto narrativo.

Estas primeiras considerações teóricas a respeito do funcionamento da narrativa já nos permitem traçar algumas condições para que um enunciado possa, a partir de uma abordagem estruturalista, ser definido como uma narrativa. Em primeiro lugar, deve haver uma relação lógico-semântica entre funções e atores para que possa haver uma proposição narrativa. Para que tenhamos um texto narrativo coerente é preciso que os fatos denotados pelas proposições narrativas estejam ligados por uma relação cronológica e lógica. Finalmente, para que haja narrativa, é preciso, também, que haja uma transformação entre uma situação ou estado inicial e a situação ou o

Psicologia: Reflexão e Crítica, 2001, 14(3), pp. 589-597 estado final que funcione como uma conclusão do texto narrativo.

"Vimos que o reagrupamento de proposições narrativas em tríades imbricadas constituem grupos de funções. São estes grupos de proposições organizadas em ciclos que formam as seqüências narrativas. Para que um grupo de proposições narrativas forme uma seqüência é preciso não somente que um mesmo ator as unifique atravessando-as, mas também que haja uma transformação" (Adam, 1985, p. 54).

Adam (1985) sintetiza nossa visão de narrativa até aqui na Figura 1.

\begin{tabular}{lcc}
\hline Situação Inicial $\rightarrow$ & Transformação $\rightarrow$ & Situação Final \\
Universo Perturbado & $\begin{array}{cc}\text { Mediação } \\
(\text { Falta })\end{array}$ & Universo Restabelecido \\
& (Provas $)$ & (Falta corrigida )
\end{tabular}

EnunciadoDeEstado $\rightarrow$ Enunc.DeFazer $\rightarrow$ Enunc. DeEstado

(Ex.: Rei velho ou doente) (Ex.: Rei jovem ou curado)

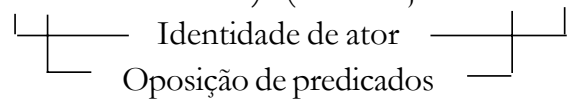

Figura 1. O esquema da narrativa em Adam

Paralelamente ao estudo de Bremond (1966), que combina uma seqüência de atos e proposições em uma ordem cronológica tal como vista acima, é elaborado um entendimento da narrativa a partir de uma ordem configuracional, baseada na compreensão de que o enunciado narrativo se organiza como uma estrutura. Veremos a seguir uma série de autores responsáveis pela elaboração de uma ordem configuracional do enunciado narrativo.

Um dos primeiros pesquisadores a chamar a atenção sobre a existência de uma estrutura no enunciado narrativo foi Jung (1945/1984). Estudando uma quantidade muito grande de sonhos, Jung reparou que o sonho tende a se organizar como um drama. Retomando o conceito aristotélico de drama, Jung afirmou que certos sonhos, os quais chamou de sonhos médios, apresentam tal estrutura. Assim os sonhos apresentam uma situação inicial, a qual Jung chamou de Exposição. Ela indica o lugar da ação, os personagens e a situação inicial do drama. A segunda fase é o Desenvolvimento da ação. Aqui, a situação inicial complica-se, estabelecendo uma tensão, porque não se sabe o que vai acontecer. Então o sonho encaminha-se para a terceira fase, a Culminação ou Peripécia, na qual acontece alguma coisa de decisivo, ou a situação muda completamente. A quarta e última fase é a Lise, Solução ou Resultado. Aqui, o problema ou a falta, apontada na dramatização onírica, resolve-se. Por exemplo: 
"Vejo-me numa rua; é uma avenida (Exposição). Ao longe aparece um automóvel que se aproxima rapidamente. Sua maneira de movimentar-se é estranhamente insegura, e eu penso que o motorista deve estar embriagado (Desenvolvimento). De repente sou eu que estou no carro e aparentemente sou eu mesmo o motorista embriagado. Estou apenas estranhamente inseguro e como que sem a direção do carro. Não consigo mais controlar o carro e vou com ele de encontro a um muro, com grande barulho (Culminação ou Peripécia). Observo que a parte dianteira do carro ficou toda amassada. É um carro alheio que eu desconheço. Eu próprio não estou ferido. Reflito com certa preocupação sobre minha responsabilidade (Lise, Solução ou Resultado)" (Jung, 1945/1984; p. 303).

É interessante notar que Jung (1945/1984) não irá empregar o termo narrativa, mas drama, utilizando, assim, a mesma terminologia empregada por Aristóteles (1992). Tal fato se explica pelo estado da arte na época. De qualquer maneira, a unanimidade entre os estudiosos da narrativa em apontar Aristóteles como seu principal precursor nos autoriza a entender, neste caso, drama como narrativa. Outro ponto que deve ser salientado é o fato de que Jung organiza sua estrutura narrativa a partir de quatro macro-proposições ${ }^{3}$ : Exposição, Desenvolvimento, Peripécia e Resultado. Encontraremos uma estruturação muito semelhante a esta nos trabalhos de Labov e Waletzky (1967), embora estes autores nos proponham uma estrutura dividida em cinco macro-proposições.

Labov e Waletzky (1967) coletaram um grande número de narrativas orais em adultos e crianças em diversas culturas, sendo sua abordagem de análise da narrativa freqüentemente utilizada por aqueles que trabalham com a narrativa oral. Labov define narrativa como um método de recapitulação de experiências passadas comparando uma seqüência verbal de proposições (clauses) com a seqüência de eventos que de fato ocorreu. Segundo ele, a narrativa vai ter duas funções fundamentais: de referência e avaliação. A função de referência aparece na transmissão de informações que encontramos na narrativa, sendo estas de lugar, tempo, personagens, de eventos - o que, o onde e o como os fatos ocorreram - a seqüência temporal das ações ou dos episódios. A função de avaliação transmite ao ouvinte o motivo da narrativa ter sido contada, tanto na forma da expressão explícita da importância da história para o narrador, como na dos juízos de valor emitidos ao longo da narrativa (Peterson

\footnotetext{
${ }^{3}$ Os conceitos de macro-estrutura narrativa e de macro-proposição narrativa foram cunhados por Adam (1984 e 1985) e aplicado às teorias do enunciado narrativo de diversos autores. Estes conceitos serão empregados daqui para frente.
}

\& McCabe, 1983). Assim, Labov e Waletzky centram sua definição de núcleo narrativo menos sobre a organização temporal e sobre o esqueleto dos eventos objetivos do que sobre a dimensão avaliativa que precisa o ponto central da narrativa, e colocando o acento sobre os eventos mais importantes.

Segundo Adam (1984), a sócio-lingüística de Labov e Waletzky (1967) entende que a narrativa, além de uma dimensão cronológico-seqüencial que ordena os elementos um após outro, comporta e necessita uma dimensão figuracional, na forma de uma macro-estrutura semântica, na qual é a "figura" que ordena os elementos um ao lado do outro. Desta forma, a narrativa vai ter uma superestrutura textual composta de macroproposições de orientação, complicação, ação ou avaliação, resolução, conclusão ou moral, dentro das quais se agrupam as proposições, estas as menores unidades da narrativa. As proposições são as sentenças, frases ou subfrases, que compõem o texto, podendo, conforme suas características, ser divididas em uma dessas categorias ou macroproposições. Labov e Waletzky definem uma narrativa mínima como "uma seqüência de duas proposições narrativas restritas, temporalmente ordenadas, de maneira que uma mudança em sua ordem resultará na mudança na seqüência temporal da interpretação semântica original" (p.27).

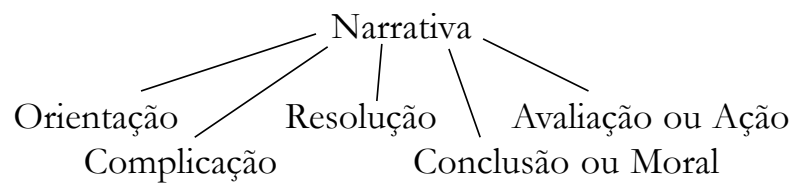

Figura 2. A organização da estrutura macroproposicional da narrativa em Labov e Waletzky

Tal esquema divide a narrativa em cinco macroproposições. Um texto narrativo inicia a partir de uma Orientação na qual são definidas as situações de espaço, tempo e características das personagens. Em seguida, ocorre uma Complicação através de uma ação que visa modificar o estado inicial e que dá início à narrativa propriamente dita. A narrativa, então, culmina no momento em que uma Ação transforma a nova situação provocada pela complicação ou em que uma Avaliação da nova situação indica as reações do sujeito do enunciado. A narrativa, então, chega a um Resultado em que é estabelecido um novo estado, diferente do estado inicial da estória. O final da narrativa se dá no momento em que é elaborada uma Moral, a partir das conseqüências da estória. Todorov (1971), a partir da crítica literária, proporá uma definição da narrativa que também aponta para uma

Psicologia: Reflexão e Crítica, 2001, 14(3), pp. 589-597 
divisão do enunciado narrativo em cinco macroproposições.

"A intriga mínima consiste na passagem de um equilíbrio a outro. Uma narrativa ideal começa por uma situação estável que uma força qualquer vem perturbar. Daí resulta um estado de desequilíbrio; por ação de uma força dirigida em sentido inverso, o equilíbrio é restabelecido; o segundo equilíbrio é semelhante ao primeiro, mas os dois nunca são idênticos. Há, por conseguinte, dois tipos de episódios na narrativa: os que descrevem um estado (de equilíbrio ou de desequilíbrio) e os que descrevem a passagem de um estado a outro" (Todorov, 1971, p. 124).

Em um trabalho posterior, Todorov (1973) destaca nesta definição a divisão da seqüência narrativa em cinco macro-proposições. O que aparecia implícito em seu trabalho anterior aparece aqui explicitado. A primeira macro-proposição (Pn1) corresponderia, assim, à situação estável inicial. A segunda (Pn2), à força que a vem perturbar. A terceira (Pn3), corresponde ao estado de desequilíbrio resultante. A quarta (Pn4), à força em sentido inverso que vem restabelecer o equilíbrio. Finalmente, a quinta (Pn5) corresponde ao novo equilíbrio estabelecido. De sorte que uma narrativa mínima é composta de dois estados distintos (Pn1 e Pn5) intermediados por uma série de macro-proposições narrativas medianas que asseguram a transformação de um estado em outro. Adam (1985) organiza o esquema narrativo de Todorov (1973) de forma bastante elucidativa:

Pn1 = Estado inicial (antes do processo)

Pn2 = Função que abre um processo (início do processo)

Pn3 $=$ Processo propriamente dito (processo)

Pn4 = Função que fecha o processo (fim do processo)

Pn5 = Resultado - Estado final (após o processo)

Esta série lógica de proposições narrativas será denominada por Todorov (1973) de Seqüência Narrativa. Mas para além da seqüência narrativa, poderemos encontrar enunciados mais complexos, nos quais agrupam-se, de maneira encadeada, mais de uma seqüência. Tais enunciados serão denominados de Textos Narrativos. A relação entre proposição, seqüência e texto narrativo pode ser formalizada, segundo Adam (1985; p.58), do seguinte modo:

$$
\begin{aligned}
& S_{n} \rightarrow(\operatorname{Pn} 1(\operatorname{Pn} 2(\operatorname{Pn} 3(\operatorname{Pn} 4(\operatorname{Pn} 5))))) \\
& T_{n} \rightarrow\left(S_{n} 1(\operatorname{Sn} 2(\operatorname{Sn} \ldots(\operatorname{Sn} x-1(\operatorname{Sn} x))))\right.
\end{aligned}
$$

Adam (1985, entretanto, de certa forma revê o modelo narrativo de Todorov (1973). Para Adam, o mais importante na seqüência narrativa mínima é a passagem e a transformação de um estado inicial (Pn1) em um estado final (Pn5), sendo as macroproposições narrativas intermediárias $(\operatorname{Pn} 2+\operatorname{Pn} 3+\operatorname{Pn} 4)$ os elementos que asseguram esta transformação. Deste modo, não encontraremos em Adam (1985) a necessidade de associarmos o estado inicial a um estado de equilíbrio, segundo ele o estado inicial pode ser equilibrado ou não. Assim, seqüência narrativa elementar pode, segundo Adam (1985), ser representada da seguinte forma:

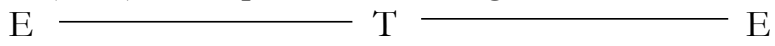

Estado inicial-Transformação ativa ou passiva - Estado final Antes — Durante (ação) D Depois Adam (1985) procede, deste modo, a passagem para um nível mais abstrato de leitura do modelo narrativo de Todorov (1973).

Na psicologia cognitiva, encontraremos a formulação de uma superestrutura proposicional da narrativa nos estudos sobre compreensão e memorização de narrativas efetuados por Mandler e Johnson (1977), Thorndyke (1977), Van Dijk (1979) e Glenn (1980), entre outros. Peterson e McCabe (1983) sintetizam a abordagem desses autores, chamando-a "análise episódica" da narrativa:

"A maioria das estórias são vistas como descrições de um comportamento dirigido para um fim. Assim, algo acontece ao protagonista que produz uma resposta interna: isto é, o desenvolvimento de uma meta. Metas são estados internos de motivação, e eles precipitam tentativas de alcançar estas metas, resultando em conseqüências bem ou mal sucedidas. Assim, a estória se constrói numa ordem lógica a partir de um motivo, passando por uma tentativa até uma conseqüência" (Peterson \& McCabe, 1983, p. 67).

Assim, Mandler e Johnson (1977) e Glenn (1980) dividem a narrativa em um Setting constituído por um estado inicial e/ou um evento, seguido por um ou mais Episódios. Cada episódio, por sua vez, comporta um início, um desenvolvimento e um fim. O setting e os episódios são organizados em um esquema de arborescência, funcionando como uma estrutura da narrativa. Já em Thorndyke (1977), encontraremos uma organização mais semelhante a de uma estrutura de macro-proposições narrativas. Segundo Thorndyke, os componentes requisitados por todas as estórias são Setting, Tema, Intriga e Resolução. A gramática de Thorndyke pode ser mais bem explicada na Figura 3.

Concluindo, esta primeira parte de nosso estudo, devemos salientar que os autores empenhados em construir o conceito de estrutura narrativa buscaram o que poderíamos chamar de esqueleto do enunciado narrativo. Eles procuraram reduzir a narrativa a sua forma mais simples e elementar, encontrando, assim, uma estrutura básica que revela a forma geral dos enunciados narrativos. Se pudéssemos sintetizar os seus estudos, talvez chegássemos a dois princípios. Podemos formular que para haver uma narrativa é preciso que haja 1) uma relação cronológica e lógica entre os eventos e as ações dos atores; e, 2) que os eventos tenham uma organização macro- 
1- Narrativa Exposição + Tema + Intriga + Resolução.

2- Exposição Personagens + Lugar + Tempo.

3- Tema Objetivo do herói + Evento.

4- Intriga Episódio(s).

5- Episódio Objetivo intermediário + Tentativa(s) + Resolução do episódio.

6- Tentativa Evento(s) ou Episódio

7- Resolução Evento e/ou Estado.

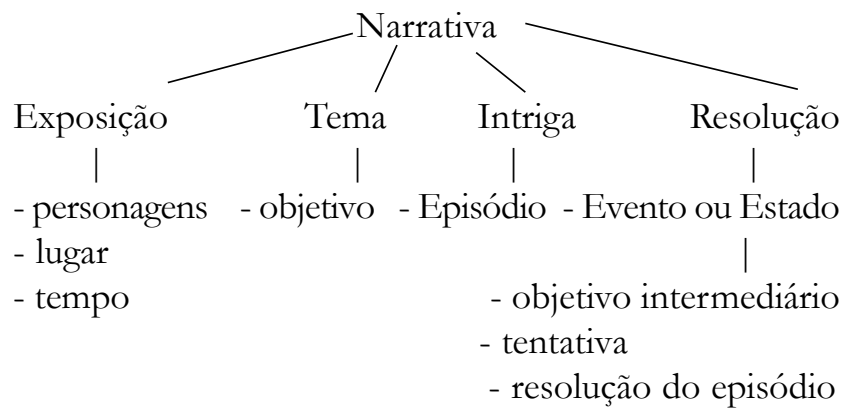

Figura 3. O esquema da narrativa em Thorndyke

proposicional. Na verdade, este segundo requisito é uma conseqüência do primeiro, pois a estrutura macroproposicional da narrativa, tal como vista pelos autores estudados, implica um ordenamento seqüencial dos eventos segundo uma lógica própria do enunciado narrativo. Como veremos a seguir, esta forma de ordenamento seqüencial passará a ser criticada por alguns autores a partir da década de 80, sendo Goodman (1981) e Ricoeur (1983/1994) alguns de seus principais representantes.

Os problemas da descronologização da narrativa e do papel do sujeito leitor foram tomados de uma forma muito interessante nos trabalhos de Goodman (1981). Em seu artigo, intitulado Twisted Tales; or Story, Study, and Symphony, Goodman analisa uma série de narrativas verbais ou em imagens, demostrando que a narrativa é capaz de suportar quase qualquer tipo de reordenamento sem deixar de ser uma narrativa. Para Goodman, a temporalidade, entendida como seqüencialidade, não pode ser apontada como um elemento distintivo da narrativa, já que, tanto no texto descritivo, como na imagem de uma situação extática, a narrativa, se não é sustentada pela enunciação ou pelo que é explicitamente enunciado, o é pela indicação que o texto nos dá sobre o que aconteceu antes, ou do que acontecerá depois da situação descrita ou pintada; isto é, pelo que é implicitamente enunciado.

"Em uma narrativa, nem a enunciação, nem o que é explicitamente enunciado necessitam ser temporizados (...) a narrativa reordenada de qualquer modo permanece sendo uma narrativa. Isto nos coloca um problema, pois nós pensamos a narrativa como aquela espécie de discurso cuja peculiaridade é a temporalidade, distinguida da descrição ou da exposição através de sua condição temporal. Nós, entretanto, não descobrimos tal condição. A temporalidade do que é implicitamente ou explicitamente dito não distingue a narrativa, pois mesmo a descrição ou a pintura de uma situação momentânea e estática implica o que aconteceu antes ou o que acontecerá depois. Uma pintura de uma floresta nos conta implicitamente sobre árvores crescendo e folhas caindo; e uma pintura de uma casa implica que árvores foram cortadas para isto" (Goodman, 1981, p. 111).

Para Goodman (1981) tanto pinturas como parágrafos tem de ser lidos como um código arbitrário. Código este, dado pelo universo cultural no qual a pintura ou texto estão inseridos. Tal concepção traz consigo o problema do leitor, o qual tem de apreender o código para conseguir ler, seja o texto ou a pintura. E é, justamente, tal elemento de convenção que se agrega ao texto ou à imagem e lhe fornece um contexto capaz de estender, através do "implicitamente dito", o seu sentido.

A narrativa, entretanto, não suporta qualquer tipo de reordenamento. Se considerarmos o relato de um psicólogo sobre o comportamento de seu paciente, não em termos de temporalidade, mas através de um agrupamento dos incidentes a partir de uma categorização qualquer, por exemplo, como sintomas: sintomas fóbicos, obsessivos, etc. neste caso não estaremos diante de uma narrativa, mas de um estudo. Para Goodman (1981), a ordenação dos eventos em categorias científicas ou estéticas transforma uma estória em um estudo ou, no segundo caso, em uma sinfonia, destruindo, assim, seu caráter de narrativa. Em fim, para Goodman a representação temporal dos eventos continua sendo um elemento distintivo da narrativa, embora tal representação não necessite mais ser expressa em termos de uma ordem seqüencial rígida. $O$ fato de os eventos estarem representados desordenadamente não destrói a narrativa.

Ricoeur (1983/1994), assim como Goodman, também critica a definição da narrativa enquanto representação do tempo em uma seqüência ordenada de eventos. Para Ricoeur, a narrativa continua sendo uma forma privilegiada de representação do tempo, embora tal representação seja demasiadamente complexa para ser expressa em termos de uma ordenação de eventos com um caráter linear. Ricoeur toma, como ponto de partida, a discussão de Santo Agostinho (398/1987) sobre a natureza do tempo. Para Santo Agostinho, o tempo tem uma natureza psicológica, já que ele só pode ser definido e medido a partir da interioridade (da alma) do homem. Se o passado já não existe, se o futuro ainda não existe e 
se o presente "voa tão rapidamente do futuro ao passado, que não tem nenhuma duração. Se a tivesse dividir-se-ia em passado e futuro. Logo o tempo presente não tem nenhum espaço" (p. 219). Como, portanto, podemos definir o tempo, e como lhe medir a duração? Agostinho continua sua investigação indagando: "se existem coisas futuras e passadas, quero saber onde elas estão. Se ainda o não posso compreender, sei, todavia que em qualquer parte onde estiverem, aí não são futuras nem pretéritas, mas presentes" (p. 220). O tempo deve, portanto, ser definido não em termos de passado, presente e futuro, mas como presente das coisas passada, presente das coisas presentes e presentes das coisas futuras.

"Existem, pois estes três tempos na minha mente que não vejo em outra parte: lembrança presente das coisas passadas, visão presente das coisas presentes e esperança presente das coisas futuras" (Santo Agostinho, 398/1987, p.222).

A noção de que o tempo tem seu lugar na alma, ou para usar a expressão de Santo Agostinho (398/1987) na Distensão da alma através dos três presentes, torna-se mais clara na discussão sobre como pode o tempo ser medido. Pois a medida do tempo acontece a partir de uma comparação subjetiva entre a duração do movimento dos corpos ou da comparação da duração entre uma sílaba longa e uma mais curta, no caso de um poema. Mas como, indaga-se Santo Agostinho, posso medir se a sílaba longa tem maior duração que a mais curta se esta só principia quando aquela termina? A resposta é, através da memória. Assim o tempo se define e se mede pela distensão da alma entre a expectação em relação ao futuro, a atenção em relação ao presente, e a memória em relação ao passado. "Aquilo que o espírito espera passa através do domínio da atenção para o domínio da memória" (p. 228). Santo Agostinho nos dá como exemplo de sua tese o recital de um hino.

"Vou recitar um hino que aprendi de cor. Antes de principiar, a minha expectação estende-se a todo ele. Porém, logo que o começar, a minha memória dilata-se, colhendo tudo o que passa de expectação para o pretérito. A vida deste meu ato divide-se em memória, por causa do que já recitei, e em expectação, por causa do que hei de recitar. A minha atenção está presente e por ela passa o que era futuro para se tornar pretérito. Quanto mais o hino se aproxima do fim, tanto mais a memória se alonga e a expectação se abrevia, até que esta fica totalmente consumida, quando a ação, já toda acabada, passar inteiramente para o domínio da memória" (Santo Agostinho, 398/1987, p. 229).

Podemos, neste momento, retomar Ricoeur (1983/ 1994), e com ele a leitura das indagações acerca do tempo em Santo Agostinho (398/1987). Ricoeur mostra que para Agostinho o tempo é entendido como representação, o Psicologia: Reflexão e Crítica, 2001, 14(3), pp. 589-597 tempo é aqui definido como experiência do tempo. Poderíamos lembrar neste momento a concepção de Kant (1781/1985), segundo a qual o espaço é a forma de nossa experiência exterior e o tempo é a forma de nossa experiência interior. Inerentes ao conceito de tempo são os conceitos de movimento e duração, seja dos corpos que observo ou das palavras que recito ou que penso. Assim, o exemplo do hino é tomado por Ricoeur como um paradigma da representação do tempo. Deste modo, o tempo encontra na narrativa a sua representação mais clara e exata, a narrativa revela-se aqui como o caráter temporal da experiência humana.

"O mundo exibido por qualquer obra narrativa é sempre um mundo temporal. (...) o tempo torna-se tempo humano na medida em que está articulado de modo narrativo; em compensação a narrativa é significativa na medida em que esboça os traços da experiência temporal” (Ricoeur, 1983/ 1994, p.15).

A partir da definição de narrativa como representação do tempo, Ricoeur (1983/1994) introduz a proposta de uma descronologização da narrativa. Se uma narrativa ordenada cronologicamente corresponde a uma representação linear do tempo, esta forma de representação, na verdade, não correspondem à experiência psicológica do tempo, vide a experiência de Santo Agostinho (398/ 1987) com o hino. Ricoeur propõe, então, que o estudo da representação da temporalidade deva não ser abolido, mas aprofundado.

O segundo pilar do edifício teórico construído por Ricoeur (1983/1994) é a Poética de Aristóteles (1992). Aqui Ricoeur centra seu estudo em torno de dois conceitos fundamentais de Aristóteles: Mimese e Muthos (Mito). Aristóteles define as artes poéticas como imitativas, entre elas a tragédia, e a comédia. O que diferencia a tragédia da comédia é o objeto que elas imitam: "Pois a mesma diferença separa a tragédia da comédia; procuram, esta, imitar os homens piores, e aquela, melhores do que ordinariamente são" (Aristóteles, 1992, III, 9). A poesia imita a vida, e é na verossimilhança com a vida que reside o seu verdadeiro valor. Não devemos, entretanto, entender imitação como cópia do real, mas como uma imitação criadora que dá espaço à ficção, e que por isso mesmo faz com que a poesia seja definida, pelo próprio Aristóteles, com sendo "algo de mais filosófico e mais sério do que a história, pois refere aquela principalmente a universal, e esta o particular" (IX, 50). Mas Aristóteles também define tragédia como "imitação de uma ação de caráter elevado” (VI, 27), e será, justamente, a partir da noção de mimese como imitação da ação que Ricoeur (1983/1994) irá aproximar mimese e mito. Os conceitos de mimese e mito coincidem no de representação (imitação) 
da ação, pois Aristóteles (1992) define Mito como "imitação de ações" (VI, 30), mas também como "composição dos atos" (VI, 30), que Ricoeur (1983/1994) traduz como "agenciamento dos fatos" (p.76). Não por acaso, a composição dos atos, que Aristóteles chama de Mito, é para nós chamada de intriga ou narrativa.

O Mito, segundo Aristóteles (1992), é por definição uma totalidade (holos), na medida em que ele deve ser a imitação de uma ação completa. Aristóteles define "Todo" como "aquilo que tem princípio, meio e fim" (Aristóteles, 1992, VII, 42). Não devemos, entretanto, confundir o conceito de totalidade da narrativa aristotélica com o de uma ordem seqüencial e cronológica necessária. Como ressalta Ricoeur (1983/1994), Aristóteles faz uma distinção entre uma ação una (completa) e de um tempo único (XXIII, 148). Deste modo, a narrativa poética seria, para Aristóteles, diferente da narrativa histórica, já que, enquanto esta última procura narrar os fatos ocorridos em um determinado período de tempo, mesmo que um não tenha relação com o outro, a narrativa poética procura narrar os fatos que representem uma ação completa. Assim, Aristóteles felicita Homero por ele ter pretendido poetar não toda a guerra de Tróia (embora ela tenha início, meio e fim), mas os fatos que envolveram a querela e o destino de Aquiles e Heitor. O recorte feito por Homero (1985) referente ao fato histórico da guerra de Tróia, permitiu circunscrever a narrativa literária em torno de uma ação una, ao contrário da multiplicidade e complexidade de ações que envolveria a narrativa de toda a guerra. Tanto é assim, que Aristóteles define Princípio, não pela ausência de antecedente, mas pela ausência de necessidade na sucessão. Fim é definido como o que sucede a outra coisa, mas "por necessidade, ou porque assim acontece na maioria dos casos" (Aristóteles, 1992, VII, 42). Somente o Meio é definido como sucessão: "é o que está depois de alguma coisa e tem outra depois de si" (VII, 42).

O que Ricoeur (1983/1994) procura nos trazer na discussão sobre o Mito, é que o agenciamento dos fatos ou a composição dos atos (que são sua definição) não organiza-se, necessariamente, em uma forma seqüencial e cronológica. $O$ que é absolutamente necessário na composição do Mito não é a organização cronológica dos eventos, mas o seu ordenamento lógico. Mas Ricoeur irá mais longe na discussão do conceito de narrativa, a partir do momento em que passa a estudar a noção de Mimese em Aristóteles.

Já vimos que para Ricoeur (1983/1994), Mimese e Mito identificam-se em um primeiro momento, já que o Mito pode ser definido como a representação da ação através do agenciamento dos fatos. Por um lado, a noção de Mimese estende-se até o caráter das personagens, por outro, até a catarse. Vimos que a tragédia se define como sendo a representação de ações de caráter elevado, ou como a imitação de homens superiores, assim como a comédia se define como sendo a imitação de homens inferiores. Pois bem, Ricoeur nos chama a atenção para o conteúdo ético da ação das personagens na tragédia como um elemento fundamental da Mimese. Isto é, não existe simplesmente a representação de ações, pois toda a ação tem um sentido ético, uma ação só pode ter como finalidade o bem ou o mal. Segundo Ricoeur (1983/ 1994), "O que constitui o objeto da representação é o homem segundo a ética. As qualificações éticas vêm do real. O que procede da imitação ou da representação é a exigência lógica de coerência" (p. 78).

Se o sentido da Mimese é a representação da vida e do homem, tal representação é impossível sem a ética. Mas seguindo o sentido da representação, devemos entender o ético também como éthos, como um "modo de vida habitual" (Peters, 1974). Retomemos Aristóteles (1992):

"No respeitante a caracteres (...) Primeiro e mais importante é que eles devem ser bons (estamos falando na tragédia). E, se, como dissemos, há caráter quando as palavras e as ações derem a conhecer alguma propensão, se esta for boa, é bom o caráter. Tal bondade é possível em toda a categoria de pessoas; com efeito, há uma bondade de mulher e uma bondade de escravo (...)" (XV, 83).

É novamente a necessidade de verossimilhança que obriga o poeta a fazer sua personagem coerente com o seu caráter, éthos também pode ser traduzido simplesmente como "caráter" (Peters, 1974).

O que Ricoeur (1983/1994) nos mostra em sua discussão do caráter como elemento mimético na Poética de Aristóteles (1992), é que há um elemento anterior à própria escrita do texto narrativo que não pode ser ignorado. O caráter das personagens nos remete ao universo simbólico da cultura, o qual diz, por exemplo, como os homens ou as mulheres devem ser ou agir em determinadas situações. Segundo Ricoeur,

"Qualquer que possa ser a força de inovação da composição poética no campo de nossa experiência temporal, a composição da intriga está enraizada numa pré-compreensão do mundo e da ação: de suas estruturas inteligíveis, de suas fontes simbólicas e de seu caráter temporal. (...) Primeiro, se é verdade que a intriga é uma imitação da ação, é exigida uma competência preliminar: a capacidade de identificar a ação em geral por seus traços estruturais; uma semântica da ação explicita esta primeira competência. Ademais, se imitar é elaborar uma significação articulada da ação, é exigida uma competência suplementar: a aptidão de identificar o que chamo de as mediações simbólicas da ação, num sentido da palavra 
símbolo que Cassirer tornou clássico e que a Antropologia cultural adotou" (p.88).

Se Ricoeur (1983/1994) qualifica o texto narrativo propriamente dito como um segundo nível da mimese, chamando-o de Mimese II, este primeiro nível, que precede o texto, será chamado de Mimese I. Aqui encontraremos todos aqueles elementos culturais, símbolos no sentido em que lhes dá Cassirer (1944/1994), que recheiam as narrativas na forma do caráter das personagens, isto é no éthos das personagens. Não encontraremos tais elementos miméticos explicitamente descritos no texto narrativo, mas indicados através do ser e do agir das personagens.

Mas para Ricoeur (1983/1994) o caráter mimético da narrativa não se esgota nestes dois níveis de mimese. Retomando novamente Aristóteles (1992), Ricoeur repara que a mimese deve se estender até a platéia para que a tragédia possa cumprir a sua finalidade de purificar os sentimentos de piedade e terror do espectador. Se a tragédia tem uma finalidade educativa, é somente a partir da identificação do espectador com o herói trágico que tal fim pode ser alcançado. A tragédia se completa neste ato de identificação, também chamado de Catarse. Tal identificação é um nível de mimese que envolve o leitor no ato de leitura do texto narrativo. Considerar a relação entre texto e leitor como pertencente ao âmbito do conceito de narrativa significa tomar a leitor como agente que reconstrói a estória no ato de leitura. Segundo Ricoeur, "o texto só se torna obra na interação entre texto e receptor" (p. 118). Isto é, há uma intersecção entre o mundo do texto e o mundo do leitor, uma "fusão de horizontes", tal como propõe H.-G. Gadamer (1970, citado por Ricoeur). Ou, como diria Ricoeur, uma teoria da escrita deve ser completada por uma teoria da leitura. A esta relação do leitor com o texto, Ricoeur chamou de Mimese III.

De algum modo, Mimese I e Mimese III se encontram, fechando uma circularidade. Isto porque, se de um lado Mimese I remete-se ao universo cultural que subjaze o texto, Mimese III traz o espectador envolvido em sua própria cultura. Como ressalta Ricoeur (1983/ 1994), tal círculo pode ser vicioso ou não. O perigo da redundância, momento em que os três níveis da Mimese atuariam confirmando-se mutuamente, de uma forma tautológica, deve ser considerado. Podemos, entretanto, dizer com Ricoeur que a intriga nem sempre representa o triunfo da ordem, que a narrativa também pode introduzir um elemento que questione e transgrida as regras sociais dadas. Tal é o caso de muitas tragédias. Por outro lado, no momento da leitura, o sujeito leitor interpõe à narrativa o seu próprio horizonte cultural e de vida, o que dá margem a múltiplas interpretações do texto narrativo. Pois como nos mostra Soares (1994) no capítulo intitulado Hermenêutica e Ciências Humanas, quando se trata de uma cultura ou de uma ideologia, temos sempre de considerar que esta ideologia não ocorre uniformemente em cada pessoa ou ator social. Há uma descontinuidade da própria ideologia, uma ruptura, por assim dizer, no momento em que o próprio ator social passa a ser visto como uma multiplicidade de individualidades, isto na medida em que ele se depara com uma sociedade caracterizada pela diferenciação nas áreas da experiência, como é o caso da metrópole contemporânea. Assim, é a própria presença da contradição dentro de uma única pessoa que dá lugar ao novo e ao inesperado na história dos movimentos sociais. Ou como escreve Ricoeur (1983/1994), "todo um leque de casos é aberto por esse fenômeno de interação: desde a confirmação ideológica da ordem estabelecida, como na arte oficial ou na crônica do poder, até a crítica social e mesmo a derrisão de qualquer real." (p. 121)

Concluindo, gostaríamos de salientar que o que este estudo nos mostra, é uma rápida passagem pela história das idéias acerca do enunciado narrativo no século XX. Em um primeiro momento, construímos um conceito geral de narrativa, uma estrutura dos enunciados narrativos. Em um segundo momentos, tivemos a necessidade de desconstruir este conceito estrutural, e isso em função de entendermos que os estudos da narrativa aplicam-se a um universo muito mais amplo do que o dos contos. $\mathrm{O}$ que Goodman (1981) aponta com o seu texto, e que Ricoeur (1983/1994) começa a sedimentar com o seu, é que estudar a narrativa significa estudar a forma como os seres humanos vivenciam e representam o tempo. Por outro lado, o estudo da narrativa também envolve o estudo de como o homem vivencia e significa o próprio mundo, a própria vida. Conforme Bruner (1990/1997),

"Começa a ficar claro porque a narrativa é um veículo tão natural para a psicologia popular. Ela lida (quase que a partir da primeira fala da criança) com o material da ação e da intencionalidade humana. Ela intermedeia entre o mundo canônico da cultura e o mundo mais idiossincrático dos desejos, crenças e esperanças. Ela torna o excepcional compreensível e mantém afastado o que é estranho, salvo quando o estranho é necessário como um tropo. Ela reitera as normas da sociedade sem ser didática. Ela pode até mesmo ensinar, conservar a memória, ou alterar o passado” (p. 52).

\section{Referências}

Adam, J-M. (1984). Le récit. Paris: Presses Universitaires de France. Adam, J-M. (1985). Le texte narratif. Paris: Nathan. 
Aristóteteles (1992). Poética (E. de Souza, Trad.). São Paulo: Ars Poética. (Original publicado em torno de 330 a.C.)

Bremond, C. (1966). La logique des possibles narratifs. Communications, 8, 60-76.

Bruner, J. (1997). Atos de significação (S. Costa, Trad.). Porto Alegre: Artes Médicas. (Original publicado em 1990)

Cassirer, E. (1994). Ensaio sobre o homem (T. R. Bueno, Trad.). São Paulo: Martins Fontes. (Original publicado em 1944)

Glenn, C. G. (1980). Relationship between story content and structure. Journal of Educational Psychology, 72, 550-560.

Goodman, N. (1981). Twisted tales; or, story, study and simphony. Em W. J. T. Mitchel (Org.), On narrative (pp. 99-116). Chicago: University of Chicago Press.

Homero (1985). A ilíada (F. C. de A. Gomes, Trad.) São Paulo: Ediouro.

Jung, C. G. (1984). Da essência dos sonhos (M. R. Rocha, Trad.). Em $A$ dinâmica do inconsciente (pp. 287-306). Petrópolis: Vozes. (Original publicado em 1945)

Kant, I. (1985). Crítica da razão pura (M. P. dos Santos, Trad.). Lisboa: Gulbenkian. (Original publicado em 1781)

Labov, W. \& Waletzky, J. (1967). Narrative analysis: Oral versions of personal experience. Em J. Helm (Org.), Essays on the verbal and visual arts (pp. 12-44). Seattle: University of Washington Press.

Mandler, J. M. \& Johnson, N. S. (1977). Remembrance of things parsed: Story structure and recall. Cognitive Psychology, 9, 111-151.
Peters, F. E. (1974). Termos filosóficos gregos. Lisboa: Gulbenkian.

Peterson, C. \& McCabe, A. (1983). Developmental psycholinguistics: Three ways of looking at a child's narrative. New York: Plenum Press.

Propp, V. (1983). Morfologia do conto (J. Ferreira \& V. Oliveira, Trads.). Lisboa: Vega. (Original publicado em 1928)

Ricoeur, P. (1994). Tempo e narrativa (C. M. César, Trad.). Campinas: Papirus. (Original publicado em 1983)

Santo Agostinho (1987). Confissões (J. O. Santos \& A. A. de Pina, Trads.). São Paulo: Nova Cultural. (Original publicado em 398)

Soares, L. E. (1994). O rigor da indisciplina. Rio de Janeiro: Relume Dumará.

Thorndyke, P. (1977). Cognitive structures in comprehension and memory of narrative discourse. Cognitive Psychology, 9, 77-110.

Todorov, T. (1971). Poética da prosa (M. de S. Cruz, Trad.). Lisboa: Edições 70. (Original publicado em 1971)

Todorov, T. (1973). Qu'est-ce que le structuralisme?: Poétique. Paris: Éditions du Seuil.

Van Dijk, T. A. (1979). Cognitive processing of literary discourse. Poetics Today, 1, 1-2.

Recebido: 09/10/2000

Revisado: 29/01/2001

Aceite Final: 08/03/2001

Sobre o autor

André Guirland Vieira é Psicólogo, Mestre em Psicologia do Desenvolvimento pelo Curso de Pós-Graduação em Psicologia do Desenvolvimento da UFRGS e Doutorando pelo mesmo programa. É integrante do Centro de Estudos Junguianos C. A. Meier. 